\title{
A unique case of a benign adrenocortical tumor with triple secretion of cortisol, androgens, and aldosterone. Development of multiple sclerosis after surgical removal of the tumor
}

\author{
Athina Markou ${ }^{1}$, Kaity Tsigou ${ }^{1}$, Dimitrios Papadogias ${ }^{1}$, Kostas Kossyvakis ${ }^{1}$, \\ Kyriakos Vamvakidis ${ }^{2}$, Theodora Kounadi ${ }^{1}$ and George Piaditis ${ }^{1}$ \\ ${ }^{1}$ Department of Endocrinology and Diabetes Center, ${ }^{2}$ Third Department of Surgery, General Hospital of Athens \\ “G. Gennimatas", Athens, Greece
}

\begin{abstract}
We present a 39-year old female with a benign adrenal tumor characterized by autonomous secretion of cortisol, androgens, and aldosterone. The patient presented with a 4-year history of hypertension and severe hirsutism. Baseline investigations revealed elevated testosterone, androstendione, and $170 \mathrm{H}$ progesterone with normal levels of dehydroepi androsterone sulfate. CT of the adrenals revealed a $2.5 \times 3.0 \mathrm{~cm}$ tumor with characteristics of an adenoma on the left adrenal gland. Pelvic ultrasound was normal. Further investigations revealed suppressed basal ACTH levels, loss of diurnal rhythm of cortisol, and failure to suppress on low dose dexamethasone suppression test, suggesting autonomous cortisol secretion by the tumor. She had an exaggerated response of $170 \mathrm{H}$ progesterone to ACTH, implying reduced 21-hydroxylase activity. An elevated plasma aldosterone concentration to plasma renin activity ratio was suggestive of hyperaldosteronism, which was confirmed by failure of aldosterone to suppress to a formal saline infusion test. Complete clinical and biochemical remission of the disease was observed after left adrenalectomy. Histology confirmed the presence of an adrenocortical adenoma. The patient developed multiple sclerosis 6 months after the operation. The flare-up of an autoimmune disease (multiple sclerosis) postoperatively could be coincidental or possibly related to the high normalization of the high cortisol levels acting as a precipitating factor.
\end{abstract}

Key words: Adrenocortical adenoma, Multiple sclerosis, Cushing's syndrome, Hyperaldosteronism 


\section{INTRODUCTION}

Hirsutism is the most evident and most disturbing clinical feature of androgen excess in women of reproductive age and is usually of ovarian origin. Polycystic ovary syndrome (PCOS) is the commonest cause of hyperandrogenaemia, with other identifiable causes being classic and non-classic congenital adrenal hyperplasia (CAH), hyperandrogenic insulin resistance, usually associated with acanthosis nigricans syndrome, and androgen-secreting neoplasms. ${ }^{1}$ Cortisol and aldosterone are the hormones most frequently secreted by adrenocortical tumors, whereas isolated androgen secretion by such tumors is extremely rare. ${ }^{2}$ Mixed cortisol and androgen secretion by adrenal adenomas have also been reported, ${ }^{3-5}$ although such a syndrome combining virilization and Cushinoid appearance is more common in adrenal carcinomas. Mixed cortisol and aldosterone secretion by adrenal adenomas have also been described. ${ }^{6,7}$ However, a benign adrenal tumor simultaneously secreting cortisol, aldosterone, and testosterone has not to our knowledge been previously reported. This rare occurrence is herein described.

\section{CASE REPORT}

A 39-year old female was presented to our department with a 4-year history of fatigue, severe hirsutism, acne, and symptoms of depression for which she had been treated with lithium. She had also been found to be hypertensive $(170 / 90 \mathrm{mmHg})$. Her menstrual cycles were regular.

On examination, her blood pressure was found to be well controlled on propranolol $25 \mathrm{mg}$ and felodipine $5 \mathrm{mg}$ daily $(120 / 80 \mathrm{mmHg})$. She had facial hair growth with a Ferriman-Gallwey score of 20, facial acne, and oily skin, and her body mass index (BMI) was 24 . The rest of the examination was unremarkable and no Cushinoid features were present.

After a washout period of her antihypertensive treatment, baseline investigations revealed significantly elevated testosterone levels at $2.8 \mathrm{ng} / \mathrm{ml}(\mathrm{NV}$ : $0.1-0.9 \mathrm{ng} / \mathrm{ml})$, androstendione $\left(\Delta_{4 \mathrm{~A}}\right)$ at $9.4 \mathrm{ng} / \mathrm{ml}$ $(\mathrm{NV}: 0.5-2.8 \mathrm{ng} / \mathrm{ml})$, and $17 \mathrm{OH}$ progesterone (17OHP) at $14.7 \mathrm{ng} / \mathrm{ml}$ (NV: 0.1-1.0ng/ml). DHEAS was well within the normal range at $2212 \mathrm{ng} / \mathrm{ml}$ (NV: 350-4300ng/ml). Plasma renin activity (PRA) was
$2.2 \mathrm{ng} / \mathrm{ml} / \mathrm{hr}(\mathrm{NV}: 1.5-5.7 \mathrm{ng} / \mathrm{ml} / \mathrm{hr})$ with elevated plasma aldosterone concentrations (PAC) of 966 pmol/L (N.R: 97-831 pmol/L). A 09.00 cortisol level was $454 \mathrm{nmol} / \mathrm{L}$ (NV: 138-690 nmol/L) with suppressed ACTH ( $<5 \mathrm{pg} / \mathrm{ml}, \mathrm{NV}$ : 9-52 pg/ml). Thyroid function was normal. Serum $\mathrm{K}^{+}$was $4.0 \mathrm{mmol} / \mathrm{L}$ and $\mathrm{Na}$ was $145 \mathrm{mmol} / \mathrm{L}$.

The hyperandrogenaemia with marked elevation of $17 \mathrm{OHP}$ raised the suspicion of an adrenal cause. CT of the adrenals revealed a left adrenal mass of $3.0 \times 2.5 \mathrm{~cm}$ with characteristics of an adenoma (homogeneous, well-defined lesion with clear margins that did not show enhancement after the administration of iv contrast material).

We therefore proceeded to further investigate the functional status of the adrenal mass. Repeated PAC was $285 \mathrm{pmol} / \mathrm{l}(10.27 \mathrm{ng} / \mathrm{dl})$ with a PRA of 0.4 $\mathrm{ng} / \mathrm{ml} / \mathrm{hr}$, giving a PAC (ng/dl) to PRA ratio of 25.68, suggestive of autonomous aldosterone secretion. After infusion of two liters of normal saline within four hours, PRA was suppressed to $0.2 \mathrm{ng} / \mathrm{ml} / \mathrm{hr}$ and $\mathrm{PAC}$ was reduced to $118 \mathrm{pmol} / \mathrm{l}$, a value which in the presence of undetectable ACTH levels is considered inadequately suppressed according to our laboratory reference range $(<50 \mathrm{pmol} / \mathrm{l})$. Potassium levels were within normal range. A short synachten test (SST) revealed an exaggerated response of $17 \mathrm{OH}$ progesterone and aldosterone (Table 1). Diurnal rhythm of cortisol was lost $(360 \mathrm{nmol} / \mathrm{l}$ and

Table 1. SST: $17 \mathrm{OH}$ progesterone, cortisol, and aldosterone response to $250 \mu \mathrm{g}$ of synachten given IV.

\begin{tabular}{cccc}
\hline $\begin{array}{c}\text { Time } \\
(\mathrm{min})\end{array}$ & $\begin{array}{c}\text { 170H progesterone } \\
(\mathrm{ng} / \mathrm{ml})\end{array}$ & $\begin{array}{c}\text { Cortisol } \\
(\mathrm{nmol} / \mathrm{l})\end{array}$ & $\begin{array}{c}\text { Aldosterone } \\
(\mathrm{pmol} / \mathrm{l})\end{array}$ \\
\hline 0 & 16.3 & 495 & 1520 \\
30 & $>25$ & 699 & 1729 \\
60 & $>25$ & 693 & 1749 \\
\hline
\end{tabular}

Expected levels of $17 \mathrm{OHP}$ after stimulation: $<9.7 \mathrm{ng} / \mathrm{ml}$

Table 2. LDDST: $0.5 \mathrm{mg}$ of dexamethasone 6-hourly for two days (expected cortisol levels $<25 \mathrm{nmol} / \mathrm{L}$ ).

\begin{tabular}{lcc}
\hline & Day $\mathbf{1}(\mathbf{0 8 . 0 0})$ & Day 3 (08.00) \\
\hline CORTISOL $(\mathrm{nmol} / \mathrm{L})$ & 394 & 538 \\
ACTH $(\mathrm{pg} / \mathrm{ml})$ & $<5$ & $<5$ \\
\hline
\end{tabular}


$500 \mathrm{nmol} / 1$ at 08.00 and 24.00 , respectively), while a low dose dexamethasone suppression test (LDDST) showed autonomous cortisol secretion (Table 2), which was in keeping with the suppressed basal ACTH levels. The catecholamines, nor-metanephrines, and VMA concentrations in a $24 \mathrm{hr}$ urine sample were within normal range, excluding the diagnosis of a pheochromocytoma. An oral glucose tolerance test (OGTT) with $75 \mathrm{gr}$ of glucose revealed a degree of insulin resistance. Further imaging with ultrasonography showed normal ovarian morphology and normal uterus.

The diagnosis of a cortisol, androgen, and aldosterone secreting adrenal adenoma was therefore made. The patient underwent left laparoscopic adrenalectomy. Postoperatively she had an uneventful recovery with no need for anti-hypertensive treatment. Repeated hormonal evaluation revealed normalization of her androgen levels: testosterone $0.2 \mathrm{ng} / \mathrm{ml}$, androstendione $0.4 \mathrm{ng} / \mathrm{ml}, 17 \mathrm{OHP} 0.8 \mathrm{ng} /$ $\mathrm{ml}$ and DHEAS $226 \mathrm{ng} / \mathrm{ml}$. PAC and active renin (AR) were within normal range at $158 \mathrm{pmol} / \mathrm{l}$ and 13.4 MU/ML (NV: 7-76MU/ML, respectively. A SST showed a marginal peak cortisol level at 506 $\mathrm{nmol} / \mathrm{l}(>580 \mathrm{nmol} / \mathrm{l})$ and a peak 17OHP level at $3.8 \mathrm{ng} / \mathrm{ml}$, which was normal. She had a normal diurnal rhythm of cortisol ( 335 and $32 \mathrm{nmol} / \mathrm{l}$ at 08.00 and 24.00, respectively), and she suppressed cortisol at $20 \mathrm{nmol} / \mathrm{l}$ after a LDDST. After completion of the LDDST, we performed an infusion of two liters of normal saline within 4 hours and the level of PAC was found to be suppressed $<50 \mathrm{pmol} / \mathrm{l}$, indicating complete cure after the tumor removal. Histology confirmed the presence of an adrenocortical adenoma with no evidence of capsular or vascular invasion.

The patient was discharged on hydrocortisone tablets to be taken during stress. Reassessment of the patient two months later showed normal adrenal function. During a follow-up period of 8 months she had complete remission of her hirsutism. A Bone Mineral Density (BMD) scan of the spine revealed osteoporosis for which she was treated with bisphosphonates. Six months postoperatively she presented to the Neurology Department with a 6-day history of gradual onset of numbness, decreased sensation and paresis of the left lower limb, and weak- ness of the left upper limb. On examination, she had impaired sensation of the left lower limb with abnormal plantar reflexes. Examination of the CSF was normal. Subsequent MRI of the brain showed lesions compatible with demyelinating disease of the right frontal and parietal lobe. She was treated with intravenous steroids for 5 days followed by clinical improvement.

\section{DISCUSSION}

We present a very rare case of a patient with a benign adrenocortical tumor and autonomous secretion of cortisol, androgens, and aldosterone. Following surgical removal of the tumor, the patient presented a clinical picture of multiple sclerosis (MS). A triple hormonal secretion (cortisol, aldosterone, and androgens) by a benign adrenocortical tumor has not previously been described.

Despite the absence of full-blown clinical Cushing's syndrome, the autonomous secretion of cortisol by the tumor was demonstrated by the loss of diurnal rhythm of cortisol, the absence of cortisol suppression on the LDDST, ${ }^{8}$ and the concurrent suppressed basal ACTH levels.

In adrenal incidentalomas, defects in the enzymatic activity of enzymes involved in steroidogenesis, such as 21-hydroxylase, 11 $\beta$-hydroxylase, $17 \alpha$ hydroxylas, and 17,20-lyase, have been described that could represent either functional impairment of the enzyme activities or gene mutations restricted to the tumor. ${ }^{9-13}$ In our case reduced activity of 21hydroxylase within the tumor (normal 17OHP levels after tumor excision) could account for the exaggerated response of $17 \mathrm{OHP}$ to $\mathrm{ACTH}$, and the increased testosterone, and $\Delta_{4 \mathrm{~A}}$ levels. Similar overresponse of 17OHP to ACTH has been described before in ten patients with sub-clinical Cushing's syndrome, ${ }^{14}$ showing that alterations in enzymatic pathways can coexist with the presence of cortisol autonomy. Co-secretion of cortisol and androgens (elevated DHEAS, $\Delta_{4 \mathrm{~A}}$, and testosterone) has also been described in six cases of adrenal tumors where there was no evidence of malignancy..$^{3-5}$ In these cases the association between hypercortisolism and hyperandrogenaemia could be explained by increased 17,20-lyase activity secondary to increased cyto- 
chrome b5 expression in the adrenal adenoma tissues, as described by Sakai et al. ${ }^{5}$ Combined cortisol and aldosterone secretion from adrenocortical adenomas has also been described. ${ }^{6,7}$ The DHEAS values, although normal prior to surgery, decreased considerably, post-operatively, possibly indicating that DHEAS was also secreted by the adenoma.

In our case there was autonomous secretion of aldosterone because of the inadequate suppression of aldosterone levels after salt loading. To date, the PAC/PRA ratio is the most widely used screening test for distinguishing patients with essential hypertension from those with possible primary aldosteronism. ${ }^{15}$ If this ratio is higher than 20 , primary hyperaldosteronism is suspected and further confirmation should be provided with salt loading and measurements of aldosterone levels. ${ }^{16,17}$ The cut-off value of aldosterone, at the end of the saline infusion that has been used in order to confirm or exclude hyperaldosteronism, varies according to different authors between $138 \mathrm{pmol} / \mathrm{l}(5 \mathrm{ng} / \mathrm{dl})$ and 270 $\mathrm{pmol} / \mathrm{l}(10 \mathrm{ng} / \mathrm{dl}){ }^{18,19} \mathrm{It}$ is quite possible that such a wide range exists because other renin independent factors influence aldosterone secretion. Among these factors ACTH is considered to be the most important one, as it has been shown to have an acute stimulatory effect on aldosterone in both normal subjects and in patients with functional adrenocortical tumors. ${ }^{20,21}$ However, its role on the interpretation of aldosterone secretion tests has not been validated to date. We therefore consider that if ACTH is suppressed (as in our case), thus eliminating its effect on aldosterone secretion, the cut-off value for aldosterone suppression after salt loading should be even lower than the currently used values. In fact, in our series of 40 subjects (with or without essential hypertension and normal CT of the adrenals), in whom we performed saline infusion (2lt of normal saline over a 4hour period) after an overnight dexamethasone suppression test (1mg dexamethasone), we have shown the cut-off value of PAC to be $50 \mathrm{pmol} / \mathrm{l}$ (unpublished data). The normal $\mathrm{K}^{+}$ levels in our patient are not incompatible with autonomous aldosterone secretion by the tumor, since normokalaemic primary aldosteronism constitutes a common presentation of the disease. ${ }^{18,22,23}$ Therefore, using these criteria we consider that our pa- tient had autonomous secretion of aldosterone in addition to cortisol and androgens. Normalization of her hormonal profile and blood pressure and remission of her hirsutism following surgery support our diagnosis.

Multiple sclerosis is a chronic demyelinating disease of the central nervous system (CNS), most probably of autoimmune pathogenesis. Both T-cell and B-cell activation with antibody formation have been shown to be implicated. ${ }^{24-27}$ Glucocorticoids exert their immunosuppressive effects through inhibition of immunoglobulin synthesis, stimulation of lymphocyte apoptosis, and inhibition of cytokine production. It is therefore possible that after the immunosuppressive effects of hypercortisolism were removed following tumor excision, our patient developed an autoimmune disease. The abrupt elimination of hypercortisolism following tumor excision possibly acted as a precipitating factor. A cortisol deprivation syndrome after cessation of suprophysiological glucocorticoid levels has been well described and favors this assumption. ${ }^{28}$

\section{REFERENCES}

1. Azziz R, Sanchez LA, Knochenhauer ES, et al, 2004 Androgen Excess in Women: Experience with Over 1000 Consecutive Patients. J Clin Endocrinol Metab 89: 453-462.

2. Danilowicz K, Albiger N, Vanegas M, Gomez RM, Cross G, Bruno O, 2002 Androgen-secreting adrenal adenomas. Obstet Gynecol 100: 1099-102.

3. Eledrisi MS, Szymajda A, Alshanti M, Lieberman SA, 2003 Visual vignette: androgen-secreting adrenal tumor with subclinical Cushing's syndrome. Endo Pract 9: 255.

4. Delgrange E, Goethals P, Laka A, Maiter D, Lambert M, 1996 An unusual case of bilateral virilizing adrenal adenoma co-secreting androgens and cortisol. J Endocrinol Invest 19: 377-381.

5. Sakai Y, Yanase T, Takayanagi R, et al, 1993 High expression of cytochrome b5 in adrenocortical adenomas from patients with Cushing's syndrome associated with high secretion of adrenal androgens. J Clin Endocrinol Metab 76: 1286-1290.

6. Allan A, Kaltsas G, Perry L, et al, 2000 Concurrent secretion of aldosterone and cortisol from an adrenal adenoma-value of MRI in diagnosis. Clin Endocrinol 53: 749-753.

7. Komiya I, Koizumi Y, Kobayashi R, Lotani M, Yamada T, Maruyama Y, 1979 Concurrent hypersecretion 
of aldosterone and cortisol from the adrenal cortical adenoma. Am J Med 30: 26-31.

8. Tsagarakis S, Kokkoris P, Roboti C, et al, 1998 The low-dose dexamethasone suppression test in patients with adrenal incidentalomas: comparisons with clinically euadrenal subjects and patients with Cushing's syndrome. Clin Endocrinol 48: 627-633.

9. Del Monte P, Bernasconi D, Bertolazzi L, Meozzi M, Badaracco B, Marugo M, 1995 Increased 17 alpha-hydroxyprogesterone response to ACTH adrenal adenoma: cause or affect? Clin Endocrinol 42: 273-277.

10. Beuschlein F, Schulze E, Mora P, et al, 1998 Steroid 21-Hydroxylase Mutations and 21-Hydroxylase Messenger Ribonucleic Acid Expression in Human Adrenocortical Tumors. J Clin Endocrinol Metab 83: 2585-2585.

11. Seppel T, Schlaghecke R, 1994 Augmented 17 alphahydroxyprogesterone response to ACTH stimulation as evidence of decreased 21-hydroxylase activity in patients with incidentally discovered adrenal tumors ('incidentalomas'). Clin Endocrinol 41: 445-451.

12. Bernini GP, Brogi G, Vivaldi MS, et al, 1996 17-Hydroxyprogesterone response to ACTH in bilateral and monolateral adrenal incidentalomas. J Endocrinol Invest 19: 745-752.

13. Sadoul JL, Kızachian B, Altare S, Hadjali Y, Canivet B, 1999 Apparent activities of 21-hydroxylase, 17a-hydroxylase and 17,20-lyase are impaired in adrenal incidentalomas. Eur J Endocrinol 141: 238-245.

14. Dall' Asta C, Barbetta L, Libe R, Passini E, Ambrossi B, 2002 Coexistence of 21-hydroxylase and 11 betahydroxylase deficiency in adrenal incidentalomas and in subclinical Cushing's syndrome. Horm Res 57: 192196.

15. Young WF, 2003 Minireview: primary aldosteronismchanging concepts in diagnosis and treatment. Endocrinology 144: 2208-2213.

16. Stowasser M, Gordon RD, Guanasekera TG, et al, 2003 High rate of detection of primary aldosteronism, including surgically treatable forms, after 'non-selective' screening of hypertensive patients. J Hypert 21: 2149-
2156.

17. Laplan NM, 2001 Cautions over the current epidemic of primary aldosteronism. Lancet 357: 953-954.

18. Bernini G, Moretti A, Argenio, Salvetti A, 2002 Primary aldosteronism in normokalaemic patients with adrenal incidentalomas. Eur J Endocrinol 146: 523529.

19. Ganguly A, 1998 Primary aldosteronism. N Engl J Med 339: 1828-1834.

20. Arvat E, Di Vito L, Lanfranco F, et al, 2000 Stimulatory Effect of Adrenocorticotropin on Cortisol, Aldosterone and Dehydroepiandrosterone Secretion In Normal Humans: Dose-Response Study. J Clin Endocrinol Metab 85: 3141-3145.

21. Mancini T, Kola B, Mantero F, Arnaldi G, 2003 Functional and Nonfunctional Adrenocortical Tumors Demonstrate a High Responsiveness to Low-Dose Adrenocorticotropin. J Clin Endocrinol Metab 88: 1994-1998.

22. Fardella CE, Mosso L, Gomez-Sanchez C, et al, 2000 Primary Hyperaldosteronism in Essential Hypertensives: Prevalence, Biochemical Profile and Molecular Biology. J Clin Endocrinol Metab 85: 1863-1867.

23. Mansmann G, Lau J, Balk E, Rothberg M, Miyachi Y, Bornstein SR, 2004 The clinically inapparent adrenal mass: update in diagnosis and management. Endocr Rev 25: 309-340.

24. Pender MP, 2004 The pathogenesis of primary progressive multiple sclerosis: antibody-mediated attack and no repair? J Clin Neurosci 11: 689-692.

25. Takahashi K, Aranami T, Endoh M, Miyake S, Yamamura T, 2004 The regulatory role of natural killer cells in multiple sclerosis. Brain 127: 1917-1927.

26. Markovic-Plese S, Pinilla C, Martin R, 2004 The initiation of the autoimmune response in multiple sclerosis. Clin Neurol Neurosurg 106: 218-222.

27. Compston A, 2004 The pathogenesis and basis for treatment in multiple sclerosis. Clin Neurol Neurosurg 106: 246-248.

28. Hochberg Z, Pacak K, Chrousos GP, 2003 Endocrine withdrawal syndromes. Endocr Rev 24: 523-538. 